\title{
Monitoramento e Avaliação dos Planos Decenais de Educação: a produção do conhecimento no Brasil
}

\section{Monitoring and Evaluation of Decennial Education Plans: the production of knowledge in Brazil}

\author{
Maria Alice de Miranda Aranda* \\ Evally Solaine de Souza Rodrigues* \\ Sílvio Cesar Nunes Militão*
}

\begin{abstract}
RESUMO
O escopo principal deste trabalho consiste em realizar um balanço sobre a produção do conhecimento referente ao monitoramento e avaliação dos planos decenais de educação, no período de 2001 a 2017, aqui compreendidos como Plano Nacional de Educação (PNE), Plano Estadual de Educação (PEE) e Plano Municipal de Educação (PME). Para esse levantamento, não se fez distinção entre as duas gerações de Planos, surgidas após o Brasil democrático de 1988 (PNE 2001-2010 e PNE 2014-2024 e os respectivos planos subnacionais) visto que se julgou relevante alcançar maior abrangência na pesquisa, a fim de contribuir com a produção do conhecimento acerca da temática em tela. De abordagem quali-quantitativa, este artigo valeu-se de pesquisa exploratória e bibliográfica e contemplou a utilização das seguintes bases de dados: a) Portal de Teses e Dissertações da Coordenação de Aperfeiçoamento de Pessoal de Nível Superior (CAPES); b) Anais resultantes das reuniões nacionais da Associação Nacional de Pós-Graduação e Pesquisa em Educação (ANPED); e c) bases de dados da Biblioteca Científica Eletrônica Online (Scielo Brasil). Os resultados mostram que ainda é muito escassa a produção do conhecimento nacional voltada aos planos decenais de educação, sobretudo se considerado o foco exclusivo no monitoramento e avaliação
\end{abstract}

${ }^{*}$ Universidade Federal da Grande Dourados. Dourados, Mato Grosso do Sul, Brasil. E-mail: mariaaranda@ufgd.edu.br. http://orcid.org/0000-0003-2561-7579. E-mail: evallyrodrigues@ gmail.com. https://orcid.org/0000-0001-6144-552X. E-mail: scnmilitao@gmail.com. https://orcid. org/0000-0003-2094-1193. 
dos Planos. Conclui-se, portanto, que tal foco de abordagem constitui-se num campo aberto e fértil para novas pesquisas.

Palavras-chave: Plano Decenal de Educação. Monitoramento. Avaliação. Produção do conhecimento.

\begin{abstract}
The main objective of this work is to carry out a balance sheet on the production of the knowledge related to the monitoring and evaluation of the decennial education plans, from 2001 to 2017, here understood as the National Plan of Education (PNE), State Plan of Education (PEE) and Municipality Education Plan (SME). For this survey, no distinction was made between the two generations of Plans, which emerged after the democratic Brazil of 1988 (PNE 2001-2010 and PNE 2014-2024 and the respective subnational plans), since it was considered relevant to reach greater scope in the research, in order to contribute to the production of knowledge about the subject matter on the screen. With a qualitative and quantitative approach, this article used exploratory and bibliographical research and contemplated the use of the following databases: a) Portal of Thesis and Dissertations of Coordenação de Aperfeiçoamento de Pessoal de Nível Superior (CAPES); b) Annals resulting from the national meetings of Associação Nacional de Pós-Graduação e Pesquisa em Educação (ANPED); and c) databases of the Electronic Scientific Library Online (Scielo Brazil). The results show that the production of national knowledge related to the 10-year education plans is still very scarce, especially if it is considered the exclusive focus in the monitoring and evaluation of the Plans. We conclude, therefore, that this focus is an open field and the fertile ground for further research.

Keywords: Decennial Education Plan. Monitoring. Evaluation. Knowledge production.
\end{abstract}

\title{
Introdução
}

O ciclo de uma política pública pode ser compreendido, para fins didáticos, em uma lógica sequencial, composto por etapas: $1^{\circ}$ ) organização da agenda; $2^{\circ}$ ) formulação da agenda; $3^{\circ}$ ) implementação; $4^{\circ}$ ) avaliação; $5^{\circ}$ ) término (PALUMBO, 1994). No entanto, no plano prático, tais etapas encontram-se interligadas e nem sempre são sequenciais. Exemplificando: ao mesmo tempo em que uma ideia é considerada para compor a agenda dos governos ela pode 
ser avaliada se, de fato, é viável seu prosseguimento, coexistindo assim dois momentos de um ciclo (organização da agenda e avaliação).

A etapa da avaliação pode estar presente nos três primeiros momentos do ciclo de políticas, contribuindo para o (re)pensar sobre uma política pública. Essa etapa é fragmentada em três partes, sendo elas: 1) análise de políticas (ocorre antes de tomar a decisão definitiva sobre uma política. Os conhecimentos essenciais para esses estudos versam sobre a economia, matemática e estatística);2) análise de processo (focaliza o processo pelo qual as políticas são traduzidas em programas e como são administrados. As disciplinas que fundamentam este estudo correspondem à ciência política e administração pública); 3) avaliação do programa (restringe-se à etapa pós-decisória que intenta determinar se um programa está alcançando suas metas, o que o programa está realizando e quem se beneficia com ele. Lança mão de estudos nas áreas da psicologia e da sociologia) (PALUMBO, 1994).

Avaliar uma política, tanto em seu processo de implementação, que pode ser compreendido como monitoramento da vida útil de uma política, bem como verificar seus desdobramentos e impactos ao término do ciclo correspondem a ações imprescindíveis para o sucesso de uma política. O contrário também é verdadeiro, ou seja, a ausência de mecanismos de avaliação periódica e a inexistência ou a parca existência de práticas avaliativas contribuem negativamente para o êxito de uma política pública.

Considerando a relevância dessa etapa do ciclo de políticas, este trabalho visa apresentar um balanço sobre a produção do conhecimento referente ao monitoramento/acompanhamento e avaliação dos planos decenais em educação, aqui compreendidos como Plano Nacional de Educação (PNE), Plano Estadual de Educação (PEE) e Plano Municipal de Educação (PME).

Com intuito de alcançar maior abrangência na pesquisa, considerou-se as duas gerações de planos, após o Brasil democrático - 1988 (PNE 2001-2010 e PNE 2014-2024 e os respectivos planos subnacionais) -, bem como um recorte temporal que possibilitasse abarcar todo o período histórico desde a promulgação do primeiro PNE até o momento atual.

Portanto, aborda-se o estado do conhecimento sobre a produção científica contida no Portal de Teses e Dissertações da CAPES, nos Anais das reuniões nacionais da ANPED e na base de dados da Biblioteca Científica Eletrônica Online (Scielo Brasil), no período 2001-2017.

Para fins de apresentação, o artigo está estruturado em quatro seções. A primeira aborda a política de planejamento educacional brasileira numa perspectiva histórica. Na sequência, apresenta e discute a produção do conhecimento sobre os planos decenais. Na terceira seção, especificamente, trata do mapeamento da produção científica relativa ao monitoramento e avaliação 
de planos decenais. Por último, são apresentadas as considerações finais em que são descritos alguns apontamentos relativos aos possíveis focos de pesquisas que podem ser empreendidos a partir das lacunas existentes nas produções analisadas.

\section{A política nacional de planejamento em educação}

A ideia de um plano educacional de "[...] Estado, para além dos governos, com dimensão nacional, de responsabilidade de todos os entes federados e abrangendo os diferentes níveis e etapas da educação" (BORDIGNON, 2009, p. 91), apesar de remontar à década de 1930 - cujo marco histórico é o "Manifesto dos Pioneiros da Educação Nova" - e ser preconizada por importantes diplomas legais, sempre encontrou fortes obstáculos à sua efetiva materialização no país como política pública. Como bem pontua Dourado (2017, p. 12):

[...] a relação entre proposição e aprovação do plano não é linear ao seu processo de materialização como política pública. Ou seja, a materialização do PNE implica ações e políticas que se efetivam, a partir de vários embates e conjunturas, que contribuem para a efetivação do plano ou para a sua secundarização.

Prova da pouca tradição do Estado brasileiro em pautar a nossa educação mediante planejamento educacional de longo prazo é que

Apenas em 1988, com a aprovação da nossa Constituição Federal é que a União é obrigada a elaborar Lei estabelecendo o Plano Nacional de Educação, de duração plurianual (art. 214), depois redefinido como decenal, com o objetivo de articular o sistema nacional de educação (EC 59/2009). O primeiro plano decenal de educação no Brasil nasce então em 2001 com a Lei 10.172 de 09 de janeiro de 2001 (NASCIMENTO; GROSSI JÚNIOR; PEREIRA, 2017, p. 110).

Acerca do processo de elaboração e aprovação do primeiro Plano Nacional de Educação (PNE) brasileiro instituído por lei específica, Scaff e Oliveira (2018, p. 143) afirmam que 
O primeiro PNE elaborado sob a égide da Constituição Federal de 1988 foi marcado pela ampla participação da sociedade brasileira, por meio de dois Congressos Nacionais de Educação (CONED) e amplos debates realizados por todo o país, sob a coordenação do Fórum Nacional em Defesa da Escola Pública (FNDEP). No entanto o projeto elaborado pela sociedade brasileira não logrou êxito, uma vez que contestava o projeto neoliberal do governo federal em curso. Após longo percurso de debates e enfrentamentos, o documento aprovado e sancionado pela Lei n.10.172, de 9 de janeiro de 2001 (BRASIL, 2001), restou comprometido diante dos limites orçamentários que impediam a concretização de suas metas.

Ao avaliar o PNE 2001-2010 já expirado, Dourado (2010, p. 685) aponta os limites à sua concretização, advindos das "[...] restrições à gestão e ao financiamento da educação, em função de nove vetos presidenciais ao que fora delineado", configurando-se como "plano formal, marcado pela ausência de mecanismos concretos de financiamento", não se efetivando, assim, como diretriz para as políticas, o planejamento e a gestão da educação nacional. Exemplo desse fato encontra-se no reduzido número de planos estaduais e municipais de educação aprovados em decorrência de tal PNE, embora se constituísse em exigência legal.

Carente de organicidade interna, exagerado quanto ao número de metas fixadas, 297 ao todo, denotando "[...] um alto índice de dispersão e perda do senso de distinção entre o que é principal e o que é acessório" (SAVIANI, 2008, p. 275) - e sem prever mecanismos concretos e eficazes para o correspondente monitoramento e avaliação da sua implementação, o PNE 2001-2010 na prática não se traduziu como mecanismo de regulação capaz de "[...] nortear as diretrizes de planejamento, gestão e efetivação das políticas educacionais, como se espera de um plano nacional que contribua para o pacto federativo" (DOURADO, 2010, p. 688).

No entanto, não obstante todos os problemas, limitações e fragilidades do PNE 2001-2010, tal Plano suscitou a esperança da sociedade civil acerca da aprovação de um próximo Plano, notadamente a sua construção mais democrática. Tal anseio esse que pode ser observado em diversos trabalhos publicados próximo ao final da vigência do Plano 2001-2010, dentre os quais podemos mencionar: Dourado (2010), Aguiar (2010), Di Pierro (2010) e Sampaio (2011).

Em meio a esse contexto de expectativa de superação dos impasses na educação e na busca pela caminhada em prol de uma educação de qualidade social, o Plano que substituiu o PNE 2001-2010 começou a ser elaborado a partir do final de 2010, consumindo cerca de três anos e meio para sua tramitação e aprovação final.

Não obstante as marchas e as contramarchas durante o longo, disputado e complexo processo de tramitação, foi aprovado pela Lei $n^{0} 13.005$, de 25 
de junho de 2014 (sem qualquer veto da então Presidente Dilma Rousseff) o PNE 2014-2024, composto por 20 Metas e 254 Estratégias voltadas a todos os níveis, etapas e modalidades de ensino, de modo a representar um novo alento em termos de planejamento educacional como política de Estado.

Diferentemente do ocorrido com o PNE de 2001, a elaboração do PNE vigente avançou ao ser fruto, também, de ampla participação da sociedade civil, notadamente nas distintas etapas da Conferência Nacional de Educação (CONAE), ocorridas em 2010 e 2014.

Outro avanço importante refere-se à estrutura do documento final aprovado, mais enxuta e objetiva. Para Saviani (2014), trata-se de aspecto positivo, uma vez que facilita o processo de monitoramento e avaliação do PNE 2014-2024.

Contudo, num cenário contemporâneo de consideráveis retrocessos políticos e de impactante "ajuste fiscal", cuja maior expressão foi a aprovação da Emenda Constitucional no 95/2016 pelo governo federal ilegítimo e antipopular de Michel Temer "[...] instalado em consequência de um golpe jurídico-midiático-parlamentar [...]" (SAVIANI, 2018, p. 45), a efetiva materialização do PNE 2014-2024 encontra-se significativamente comprometida.

Assim, é premente a "[...] efetiva mobilização e participação da sociedade civil e política no monitoramento, avaliação e materialização do novo PNE (2014-2024), a fim de que este plano se constitua em efetiva política de Estado para a educação" (DOURADO, 2017, p. 19).

Considerando a relevância dos planos decenais para delinear os rumos da educação nacional, passa-se para a próxima seção na qual será apresentado o mapeamento da produção brasileira do conhecimento em nível de mestrado/ doutorado e de artigos/trabalhos científicos oriundos de pesquisas independentes a respeito da temática.

\section{PNE, PEE e PME: a produção do conhecimento no Brasil}

Caracteriza-se a pesquisa como qualitativa e quantitativa (TRIVIÑOS, 2007), de caráter bibliográfico e documental, uma vez que se trata de um levantamento ordenado, analítico, descritivo e crítico (TEIXEIRA, 2006) da produção do conhecimento sobre os planos decenais de educação, com enfoque no processo de monitoramento e avaliação dessa política.

Recorreu-se a tal abordagem por considerá-la condizente com a demanda requerida pelo objeto de estudo, bem como a relação que se estabelece com o pesquisador. Além disso, adotou-se essa estratégia por compreender que se 
trata de uma "metodologia de caráter inventariante e descritivo da produção acadêmica e científica" (FERREIRA, 2002, p. 259).

A pesquisa começou pelo levantamento de tudo o que se tinha produzido sobre planos decenais (PNE, PEE e PME) no período de 2001 a 2017, no portal de teses e dissertações da CAPES, localizado a partir dos descritores "plano nacional de educação" "plano estadual de educação" e "plano municipal de educação". No primeiro momento, obteve-se 582 resultados $^{1}$. Na sequência, foi feita a separação dos trabalhos que realmente abordavam os planos decenais como questão central, através da leitura dos títulos. Quando apenas o título da pesquisa não clarificava o escopo do trabalho, recorreu-se também à leitura dos resumos.

Restaram, portanto, 85 pesquisas do universo de 582 trabalhos publicados no portal de teses e dissertações da CAPES, no período de 2001 a 2017, conforme demonstra a Tabela 1.

TABELA 1 - DISTRIBUIÇÃO DE PESQUISAS COM FOCO NOS PLANOS DECENAIS EM RELAÇÃO AOS TRABALHOS TOTAIS DO PORTAL CAPES E GT-5²/ANPED (2001-2017)

\begin{tabular}{|c|c|c|c|c|c|c|}
\hline \multirow{3}{*}{ Ano } & \multirow{2}{*}{\multicolumn{2}{|c|}{$\begin{array}{l}\text { Qtd. de trabalhos localizados } \\
\text { a partir dos descritores "PNE" } \\
\text { "PEE" "PME" }\end{array}$}} & \multicolumn{4}{|c|}{ Pesquisas com foco em planos decenais } \\
\hline & & & \multicolumn{2}{|c|}{$\begin{array}{c}\text { Portal } \\
\text { CAPES }\end{array}$} & \multicolumn{2}{|c|}{$\begin{array}{c}\text { ANPED } \\
\text { NACIONAL }\end{array}$} \\
\hline & $\begin{array}{c}\text { Portal } \\
\text { CAPES }\end{array}$ & $\begin{array}{c}\text { ANPED } \\
\text { NACIONAL }\end{array}$ & $\mathbf{N}^{\circ}$ & $\%$ & $\mathbf{N}^{\circ}$ & $\%$ \\
\hline 2001 & 4 & 19 & 0 & $0,00 \%$ & 1 & $5,26 \%$ \\
\hline 2002 & 7 & 9 & 0 & $0,00 \%$ & 0 & $0,00 \%$ \\
\hline 2003 & 7 & 20 & 0 & $0,00 \%$ & 0 & $0,00 \%$ \\
\hline 2004 & 7 & 21 & 2 & $28,57 \%$ & 0 & $0,00 \%$ \\
\hline 2005 & 3 & 15 & 2 & $66,67 \%$ & 0 & $0,00 \%$ \\
\hline 2008 & 16 & 16 & 3 & $18,75 \%$ & 0 & $0,00 \%$ \\
\hline
\end{tabular}

CONTINUA

1 Cumpre informar que, complementarmente, também foram empreendidas buscas no sítio eletrônico do Instituto Brasileiro de Informação em Ciências e Tecnologia (IBICT), cujos resultados foram semelhantes aos encontrados no Portal da CAPES. Por esta razão, bem como considerando o espaço-limite deste artigo, optamos por não apresentar/detalhar o levantamento efetuado no sítio do IBICT.

2 Grupo de Trabalho Estado e Política Educacional da ANPED. 
CONCLUSÃO

\begin{tabular}{|c|c|c|c|c|c|c|}
\hline \multirow{3}{*}{ Ano } & \multirow{2}{*}{\multicolumn{2}{|c|}{$\begin{array}{c}\text { Qtd. de trabalhos localizados } \\
\text { a partir dos descritores "PNE" } \\
\text { "PEE" "PME" }\end{array}$}} & \multicolumn{4}{|c|}{ Pesquisas com foco em planos decenais } \\
\hline & & & \multicolumn{2}{|c|}{$\begin{array}{c}\text { Portal } \\
\text { CAPES }\end{array}$} & \multicolumn{2}{|c|}{$\begin{array}{c}\text { ANPED } \\
\text { NACIONAL }\end{array}$} \\
\hline & $\begin{array}{c}\text { Portal } \\
\text { CAPES }\end{array}$ & $\begin{array}{c}\text { ANPED } \\
\text { NACIONAL }\end{array}$ & $\mathbf{N}^{\circ}$ & $\%$ & $\mathbf{N}^{\circ}$ & $\%$ \\
\hline 2009 & 18 & 12 & 1 & $5,56 \%$ & 0 & $0,00 \%$ \\
\hline 2010 & 26 & ----- * & 4 & $15,38 \%$ & ----- * & $----*^{*}$ \\
\hline 2011 & 26 & 22 & 3 & $11,54 \%$ & 0 & $0,00 \%$ \\
\hline 2012 & 30 & 19 & 4 & $13,33 \%$ & 0 & $0,00 \%$ \\
\hline 2013 & 43 & 17 & 5 & $11,63 \%$ & 2 & $11,76 \%$ \\
\hline 2014 & 55 & ----- *** & 5 & $9,09 \%$ & $-----* *$ & $-----* *$ \\
\hline 2015 & 79 & 30 & 11 & $13,92 \%$ & 1 & $3,33 \%$ \\
\hline 2016 & 102 & $----{ }^{*} *$ & 16 & $15,69 \%$ & ----- ** & ----- ** \\
\hline 2017 & 134 & 23 & 25 & $18,66 \%$ & 1 & $4,34 \%$ \\
\hline Total & 582 & 264 & 85 & $14,60 \%$ & 5 & $1,89 \%$ \\
\hline
\end{tabular}

FONTE: Elaboração própria dos autores. Notas: (*) Dado não disponível para consulta durante o período de realização da pesquisa. (**) Ano em que não ocorreu reunião nacional da ANPED, a qual passou a ser bianual.

Com os dados da Tabela 1, nota-se que, após um triênio (2001-2003) de completo silenciamento, somente a partir do ano de 2004 é que começam a ser defendidas as primeiras pesquisas em nível de pós-graduação stricto sensu voltadas especificamente à temática do planejamento decenal em educação. Entretanto, a quantidade de trabalhos dedicados ao tema em abordagem permanece muito incipiente até os primeiros anos da década seguinte.

A baixíssima incidência do tema na produção acadêmica da área está relacionada, possivelmente, à histórica secundarização/insucesso de pautar a educação brasileira mediante planos decenais e ao correspondente desinteresse dos pesquisadores pela abordagem de tal temática. Ressalte-se que é apenas a partir da última redemocratização do país (1988) que a questão do planejamento educacional de longo prazo toma centralidade e ganha materialidade, deixando de ser mero espectro, sobretudo após 2001, com a promulgação do primeiro PNE. 
Ainda pela análise da Tabela 1, observa-se um grande salto na quantidade de trabalhos em nível de pós-graduação com foco nos planos decenais de educação a partir do ano de 2015, denotando um significativo amadurecimento das reflexões/interesse acerca do tema, sobretudo após as edições da CONAE (2010 e 2014). Assim, do ano de 2015 para 2017, a produção do conhecimento concernente mais que dobrou, uma vez que consta 11 trabalhos publicados em 2015 e 25 pesquisas em 2017. Não obstante tal crescimento, ainda assim, pode-se considerar ínfimo o quantitativo de investigações voltadas à questão do planejamento educacional em nível sistêmico, tema altamente relevante visto a importância do ato de planejar.

A escassez de pesquisas sobre a temática constatada no Portal de Teses e Dissertações da CAPES também observa-se em relação ao sítio eletrônico da ANPED, que abriga os trabalhos científicos apresentados nas suas reuniões nacionais. Seguindo o mesmo rigor e percurso metodológico para o levantamento e tratamento dos dados oriundos do Portal da CAPES, foram empreendidas buscas no site da ANPED, mais especificamente, no GT-5 (grupo de trabalho voltado para as políticas públicas e educacionais). O quantitativo de trabalhos produzidos e publicados no GT-5/ANPED Nacional, no período pesquisado, corresponde a 264 artigos, dos quais restaram apenas 5 com foco voltado aos planos decenais (Tabela 1).

Verifica-se, pelos dados da Tabela 1, que, apesar do primeiro trabalho com foco nos planos decenais ser publicado no GT-5/ANPED Nacional em 2001, por 11 anos ininterruptos (de 2002 a 2012) a temática permanece completamente ausente nas publicações do GT supracitado. Tal constatação expressa, sem dúvida, o grande desinteresse e o pouco investimento na temática por parte dos pesquisadores, sobretudo dos que estão ligados ao campo de investigação das políticas educacionais, via de regra reunidos no GT-5.

Os dados mostram, ainda, que o quantitativo de trabalhos/publicações nas reuniões da ANPED Nacional com foco no tema em questão só toma impulso e constância a partir do ano de 2013, chegando-se ao total de 4 trabalhos até 2017. Ainda assim, pode-se afirmar ser diminuta a produção científica acerca dos planos decenais de educação encontrada no GT-5/ANPED Nacional, sendo inclusive inferior - tanto em termos absolutos quanto relativos - aquela registrada no Portal de Teses e Dissertações da CAPES no período correspondente.

A parca produção do conhecimento sobre planos decenais levou os autores ao questionamento inicial sobre o quantitativo de pesquisas voltadas para as etapas do ciclo de política, posteriormente, por considerar que do tema "planos decenais" emergem outras temáticas relevantes para a área da educação a serem investigadas. Portanto, empreendeu-se a distribuição dos trabalhos localizados por categorias temáticas. 
Cumpre esclarecer que tais categorias não foram criadas de forma aleatória pelos pesquisadores, mas surgiram a partir do foco central dos trabalhos identificados por meio da leitura do título e resumos de todas as investigações levantadas pela pesquisa em tela no Portal da CAPES (85 trabalhos) e sítio eletrônico da ANPED Nacional (5 trabalhos), que abordavam os planos como aspecto fulcral.

O resultado da distribuição temática dos trabalhos provenientes de pesquisas de mestrado e doutorado pode ser acompanhado por meio da Tabela 2.

TABELA 2 - DISTRIBUIÇÃO DOS TRABALHOS OBTIDOS NO PORTAL CAPES, SEGUNDO CATEGORIAS TEMÁTICAS

\begin{tabular}{cc}
\hline Categorias temáticas & Qtd. de trabalhos \\
\hline Processo de elaboração de planos & 34 \\
Comparação entre planos & 8 \\
Processo de implementação de planos & 5 \\
Concepção de gestão nos planos & 4 \\
Representação social & 4 \\
Financiamento & 3 \\
Qualidade da educação & 3 \\
Formação docente & 3 \\
Gênero & 3 \\
Acompanhamento e avaliação de planos & 2 \\
Direito à educação & 2 \\
Conciliação política & 2 \\
Outras Temáticas Diversas* & 12 \\
\hline Total & $\mathbf{8 5}$ \\
\hline
\end{tabular}

FONTE: Elaboração própria dos autores. Nota (*): Nesta categoria geral, estão agrupadas 12 temáticas diversas, com uma só frequência de aparição cada.

A distribuição de trabalhos por categorias temáticas resultou em 24 categorias distintas, isto é, cada trabalho analisado, ao tratar dos planos decenais como questão central, abordava-o dentro de uma perspectiva temática diferente. Em alguns casos, embora haja particularidades nas pesquisas, há reincidência de temáticas. Assim, algumas categorias temáticas se destacam em termos de frequência de aparição no conjunto dos trabalhos pesquisados, a saber: Processo 
de elaboração de planos (34); Comparação entre planos (8); Processo de implementação de planos (5); Concepção de gestão nos planos (4); Representação social (4); Financiamento (3); Qualidade da educação (3); Formação docente (3); Gênero (3); Acompanhamento e avaliação de planos (2); Direito à educação (2); e Conciliação política (2).

Considera-se que todas as temáticas abordadas pelos pesquisadores apresentam relevância para o campo educacional. Porém, registra-se certo desequilíbrio quantitativo de pesquisa por temática. Assim, pode-se afirmar que temáticas candentes do campo da educação contemporânea não têm sido abordadas a contento pelas pesquisas da área, como o financiamento da educação, a qualidade educacional e a formação docente.

No tocante ao financiamento no âmbito dos planos de educação, é possível afirmar que esta temática ainda não foi suficientemente abordada, ainda mais se considerarmos que trata-se de aspecto imprescindível para a concretização do planejamento educacional de longo prazo, que demanda recursos significativos. Aliás, como bem destaca Saviani (2008, p. 317), num plano decenal, o financiamento da educação é “[...] a meta das metas [...], já que se constitui como a condição prévia e mecanismo de viabilidade de todas as demais metas".

Outros dois temas centrais para o avanço da educação brasileira que precisam ser mais explorados nas pesquisas acerca dos planos são: a qualidade da educação e a formação docente.

A qualidade da educação, que não é tema novo e se constitui num "[...] fenômeno complexo, abrangente e que envolve múltiplas dimensões" (DOURADO, 2007, p. 9), precisa ser retomado com maior ênfase “[...] no âmbito dos debates sobre as políticas públicas de educação, considerando o lugar que ocupa no PNE” (ARANDA; LIMA, 2014, p. 308).

A formação de professores, por sua vez, é, indiscutivelmente, uma das cruciais dimensões que concorre para o alcance da qualidade da educação, uma vez que "[...] não existe educação de qualidade sem docente de qualidade" (LEITE et al., 2010, p.102).

O desequilíbrio quantitativo reincide também quando analisada as investigações voltadas para o ciclo de políticas. Nota-se que o maior número de trabalhos está ancorado no processo de formulação e elaboração da política (34 trabalhos), seguido das que abordam o processo de implementação (5 trabalhos). Por fim, figuram as pesquisas voltadas para o processo de monitoramento e avaliação de políticas (2 trabalhos).

No âmbito dos trabalhos contidos na página eletrônica da ANPED Nacional, GT-5, percebe-se certa dissonância em alguns aspectos com a categorização dos trabalhos em nível de pós-graduação stricto sensu. 
TABELA 3 - DISTRIBUIÇÃO DOS TRABALHOS COM FOCO NOS PLANOS DECENAIS CONTIDOS NO GT-5/ ANPED NACIONAL (2001-2017) SEGUNDO CATEGORIAS TEMÁTICAS

\begin{tabular}{cc}
\hline Categorias temáticas & Qtd. de trabalhos \\
\hline Educação indígena & 1 \\
Constituição histórica dos planos & 1 \\
Eleição de diretores & 1 \\
Valorização docente & 1 \\
Expansão da educação infantil & 1 \\
\hline Total & $\mathbf{5}$ \\
\hline
\end{tabular}

FONTE: Elaboração própria dos autores.

As categorias temáticas que emergem dos artigos publicados nos anais da ANPED Nacional são proporcionais ao quantitativo de trabalhos e destoam das categorias contidas na Tabela 2 - a única temática reincidente corresponde à valorização docente ${ }^{3}$-, o que denota que o foco de interesse desse grupo de pesquisadores é distinto daquele oriundo do Portal CAPES, o que pode ser visto como aspecto favorecedor, uma vez que se amplia o foco de discussão sobre os planos decenais, produzindo conhecimento em múltiplas temáticas sobre os planejamentos decenais e apontando indicativos de lacunas existentes para que outros pesquisadores possam avançar nas discussões, enriquecendo o campo de estudo.

Trabalhos esparsos que são reveladores para o âmbito educacional podem ser encontrados a partir da década de 1920, porém é somente a partir de meados de 1980 que ocorre a intensificação de produções acadêmicas, bem como a diversificação temática de trabalhos, graças ao início da expansão e solidificação do ensino superior e de programas de pós-graduação no Brasil (GATTI, 2010).

Concomitantemente, as pesquisas na área das políticas públicas tem alcançado crescimento quantitativo a partir da década de 1960, período em que a área de políticas públicas passa a se constituir como um campo de investigação científica, devido a uma série de fatores históricos, como: a criação da Associação Nacional de Política e Administração da Educação (ANPAE/1961); a implantação da pós-graduação no Brasil (1965); a criação de periódicos na área da educação (1971); a ANPED (1976); e a criação do GT 5 - Estado e política educacional (1986/1987). No entanto, a expansão de fato desse campo de pesquisa ocorre na viragem de século (a partir das décadas de 1990/2000), com a criação de linhas e grupos de pesquisa de política educacional; a criação

3 Temática que na Tabela 2 encontra-se dentro da categoria geral "Outras Temáticas Diversas". 
da disciplina de política educacional; a criação de periódicos de política educacional; a ampliação de eventos científicos especializados; e a criação de redes de pesquisa de/sobre política educacional (STREMEL, 2016), fortemente relacionadas à hegemonia neoliberal e os decorrentes processos de reforma do Estado/da educação, que se tornaram objeto de estudo em muitas frentes de pesquisa e alvo de inúmeros pesquisadores voltados ao exame crítico acerca da política educacional brasileira.

Esses fatos históricos apontam que as pesquisas em educação, de modo geral, vêm crescendo nos últimos anos e que esse crescimento, bem como o fortalecimento, sobretudo no campo de investigação das políticas públicas, é muito recente, o que implica em poucas produções na área; reflexo disso é o quantitativo ínfimo de pesquisas voltadas para os planos decenais, mesmo sendo uma temática relevante para área educacional, assim como para o campo das políticas públicas. Isso indica a necessidade de investimento em pesquisas direcionadas a essa temática, e que esse investimento se constitui em um escopo profícuo de pesquisa.

Com o intuito de aprofundar nas discussões sobre a produção de conhecimento acerca dos planos decenais, na próxima seção serão abordados com maior profundidade as questões concernentes às produções voltadas para o monitoramento e avaliação de políticas públicas.

\section{Mapeamento da produção científica: o monitoramento e avaliação de planos decenais}

$\mathrm{O}$ ato de avaliar uma política de planejamento não corresponde a uma etapa isolada, mas em "[...] um dos componentes do processo de avaliação" (KIPNIS; ALGARTE, 2001, p. 153), ou seja, a avaliação de planos decenais não deve ser compreendida como atividade estanque ao processo de planejamento, uma vez que um dos objetivos do acompanhamento e avaliação de um planejamento é verificar as possíveis lacunas para que soluções sejam apresentadas, os ajustes necessários sejam empreendidos e os objetivos plenamente alcançados.

Além disso, o acompanhamento e avaliação dos Planos passam a ser entendidos não apenas como instrumento articulado à correção dos seus rumos pelos governos, mas como forma política voltada à prestação de contas dos governos em relação à sociedade, com vistas ao conhecimento do seu desempenho ou resultados, impactos e efeitos (DRAIBE, 2001). 
O reconhecimento da relevância do processo de monitoramento e avaliação dos planos decenais de educação, embora sinalizado de modo aligeirado no PNE/2001 (Art. $3^{\circ}$, parágrafos $\S 1^{\circ}$ e $\S 2^{\circ}$ ), ganhou maior repercussão com o PNE/2014. No Art. $5^{\circ}$, desse documento, estabelece-se a obrigatoriedade de monitoramento contínuo e avaliação periódica das metas do Plano, realizados pelo Ministério da Educação (MEC), Comissão de Educação da Câmara dos Deputados e Comissão de Educação, Cultura e Esporte do Senado Federal, Conselho Nacional de Educação (CNE) e Fórum Nacional de Educação.

Em decorrência da determinação legal contida no PNE/2014 sobre o acompanhamento ininterrupto e avaliação em intervalos de tempo determinados em relação às metas do documento, os estados e municípios também tiveram que se organizar para instaurar suas respectivas comissões de monitoramento e avaliação dos Planos.

Devido à relevância das ações de monitoramento e avaliação dos planejamentos decenais, nesta etapa da pesquisa, buscou-se o levantamento de dados que respondessem aos critérios elencados para aprofundamento no estudo, agora com o foco na produção do conhecimento sobre o monitoramento e avaliação de planos decenais em sua complexidade.

Agregado aos resultados localizados sobre a etapa de avaliação de política de planejamento sistêmico no portal de teses e dissertações da CAPES e na página eletrônica da ANPED Nacional, GT 5; ampliou-se o quantitativo de trabalhos através de pesquisas empreendidas no sítio digital do Scielo Brasil, equivalente ao período de 2001 a 2017.

No total, localizou-se 4 trabalhos no portal da CAPES, 1 trabalho na página da ANPED (cujo foco era sobre valorização docente, porém no viés da avaliação de metas do PNE/2014-2024) e 4 trabalhos no Scielo Brasil. Feita a seleção do material, realizou-se o processo de lapidação dos dados. Para tanto, foram empreendidas leituras dos trabalhos de forma integral, não apenas dos resumos. A primeira leitura teve como foco principal analisar se aquela produção de fato se inseria na temática pesquisada. Finalizada essa etapa, apenas 2 dissertações foram excluídas, visto que embora no resumo aparentava ter relação com a questão da avaliação de política decenal, o teor do trabalho completo não sinalizava o mesmo.

Para a realização da segunda etapa de leitura, os autores criaram uma ficha de leitura, contendo critérios essenciais para responder à investigação que se propõe, como: identificar os tipos de pesquisas (mestrado, doutorado, pesquisa paralela, etc.), base de dados provenientes, tema pertencente, objeto de estudo, recorte temporal, enfoque de pesquisa, distribuições regionais, tendências existentes em termos de metodologias de pesquisa adotadas e apontamentos de possíveis focos de investigação científica a partir da produção existente. 
Os critérios elencados para subsidiar a análise das produções localizadas no portal da CAPES, ANPED Nacional e Scielo Brasil seguem apresentados no Quadro 1.

\section{QUADRO 1-APRESENTAÇÃO E CARACTERIZAÇÃO DOS TRABALHOS SOBRE MONITORAMENTO E AVALIAÇÃO DE PLANOS DECENAIS CONTIDOS NO PORTAL CAPES, SCIELO BRASIL E GT-5/ANPED NACIONAL}

\begin{tabular}{|c|c|c|c|c|c|c|}
\hline Título & $\begin{array}{c}\text { Tipo de } \\
\text { pesquisa }\end{array}$ & \begin{tabular}{|l|} 
Base de dados \\
\end{tabular} & Tema & Objeto & $\begin{array}{c}\text { Recorte } \\
\text { temporal }\end{array}$ & Enfoque \\
\hline $\begin{array}{l}\text { O Plano Municipal de } \\
\text { Educação de Benevides- } \\
\text { PA: processo de } \\
\text { monitoramento e avaliação }\end{array}$ & $\begin{array}{l}\text { Mestrado } \\
\text { profissional }\end{array}$ & $\begin{array}{l}\text { Portal de teses e } \\
\text { dissertações } \\
\text { CAPES }\end{array}$ & $\begin{array}{l}\text { Monitoramento e } \\
\text { avaliação de } \\
\text { planos decenais } \\
\text { em educação }\end{array}$ & $\begin{array}{l}\text { PME/Benevides- } \\
\text { PA }\end{array}$ & $\begin{array}{l}\text { Não } \\
\text { especifícado }\end{array}$ & $\begin{array}{l}\text { Propor subsídios para o } \\
\text { monitoramento e avaliação } \\
\text { do PME de Benevides-PA. }\end{array}$ \\
\hline $\begin{array}{l}\text { Ações Participativas na } \\
\text { Elaboração e no } \\
\text { Monitoramento do PME de } \\
\text { São Caetano do Sul-SP } \\
\end{array}$ & $\begin{array}{l}\text { Mestrado } \\
\text { profissional }\end{array}$ & $\begin{array}{l}\text { Portal de teses e } \\
\text { dissertações } \\
\text { CAPES }\end{array}$ & $\begin{array}{l}\text { Elaboração e } \\
\text { monitoramento } \\
\text { de planos } \\
\text { decenais }\end{array}$ & \begin{tabular}{|l|} 
PME de São \\
Caetano do Sul- \\
SP (2015-2025) \\
\end{tabular} & $\begin{array}{l}\text { Não } \\
\text { especificado }\end{array}$ & $\begin{array}{l}\text { Analisar a participação } \\
\text { social nos processos de } \\
\text { elaboração e } \\
\text { monitoramento do PME } \\
\text { local. }\end{array}$ \\
\hline $\begin{array}{l}\text { Acompanhamento e } \\
\text { Avaliação dos/nos Planos } \\
\text { Estaduais de Educação } \\
\text { 2001-2010 }\end{array}$ & Artigo & Scielo Brasil & $\begin{array}{l}\text { Monitoramento e } \\
\text { avaliação de } \\
\text { planos decenais } \\
\text { em educação }\end{array}$ & \begin{tabular}{|l|} 
PEEs de todos \\
os estados da \\
federação - 2001 \\
2010
\end{tabular} & $2001-2010$ & $\begin{array}{l}\text { Avaliação dos PEEs no } \\
\text { período de vigência do } \\
\text { PNE 2001-2010. }\end{array}$ \\
\hline $\begin{array}{l}\text { Avaliação do Plano } \\
\text { Nacional de Educação } \\
\text { 2001-2009: questões } \\
\text { estruturais e conjunturais } \\
\text { de uma política }\end{array}$ & Artigo & Scielo Brasil & $\begin{array}{l}\text { Planejamento } \\
\text { educacional }\end{array}$ & PNE-2001/2010 & 2001-2009 & \begin{tabular}{|l} 
Avaliação do PNE- \\
2001/2010, a lógica política \\
de sua tramitação, \\
aprovação pelo Congresso \\
Nacional e o processo de \\
implementação. \\
\end{tabular} \\
\hline $\begin{array}{l}\text { Avaliação do Plano } \\
\text { Nacional de Educação } \\
\text { 2001-2009: questões para } \\
\text { reflexão }\end{array}$ & Artigo & Scielo Brasil & $\begin{array}{l}\text { Planejmaento } \\
\text { educacional }\end{array}$ & PNE-2001/2010 & 2001-2009 & $\begin{array}{l}\text { Desdobramentos do } \\
\text { PNE/2001-2010 para sua } \\
\text { efetivação. Avaliação, de } \\
\text { forma geral, os } \\
\text { (in)sucessos desse } \\
\text { documento. }\end{array}$ \\
\hline $\begin{array}{l}\text { A Educação de jovens e } \\
\text { adultos no Plano Nacional } \\
\text { de Educação: avaliação, } \\
\text { desafios e perspectivas }\end{array}$ & Artigo & Scielo Brasil & $\begin{array}{l}\text { Planejamento } \\
\text { educacional }\end{array}$ & PNE-2001/2010 & 2001-2009 & $\begin{array}{l}\text { Contextualização e } \\
\text { avaliação dos resultados do } \\
\text { PNE-2001/2010, } \\
\text { evidenciando as metas para } \\
\text { a EJA. }\end{array}$ \\
\hline $\begin{array}{l}\text { Desafios para o } \\
\text { Monitoramento da } \\
\text { Valorização Profissional no } \\
\text { Contexto da Meta } 17\end{array}$ & Artigo & $\begin{array}{l}\text { GT }-5 \text { da } \\
\text { ANPED } \\
\text { Nacional }\end{array}$ & $\begin{array}{l}\text { Monitoramento e } \\
\text { avaliação de } \\
\text { planos decenais } \\
\text { em educação }\end{array}$ & $\begin{array}{l}\text { Meta } 17 \text { do PNE } \\
2014 / 2024\end{array}$ & $\begin{array}{l}\text { Não } \\
\text { especificado }\end{array}$ & $\begin{array}{l}\text { Discutir sobre o } \\
\text { monitoramento e } \\
\text { realização da meta } 17 \text { do } \\
\text { PNE-2014/2024. }\end{array}$ \\
\hline
\end{tabular}

FONTE: Elaboração própria dos autores.

Por meio dos dados levantados e explicitados no Quadro 1, percebe-se que a produção do conhecimento com foco no monitoramento e/ou avaliação de planejamento decenal é ainda ínfima. Em nível de pós-graduação stricto sensu, registra-se apenas duas (ou 28,57\% do total) pesquisas, sendo ambas de mestrado. 
A ausência de investigações no âmbito do doutorado abordando a temática em tela pode estar provavelmente relacionada com o fato da pós-graduação brasileira oferecer " [...] muito mais cursos de mestrado do que de doutorado, com tempo de duração mais curto e mais vagas oferecidas, o que explica a maior produção de dissertações [...]" (SILVA; ALMEIDA; CAIADO, 2017, p. 865).

Essas pesquisas, embora realizadas em estados diferentes (PA e SP), possuem características semelhantes, uma vez que ambas elegeram como objeto de estudo planos municipais de educação. Além disso, esses dois trabalhos versam para uma análise propositiva, isto é, procuram sinalizar mecanismos de monitoramento e avaliação de planejamento.

Quanto às demais pesquisas localizadas (5 ou $71,43 \%$ do total encontrado), estas se enquadram na modalidade artigo científico, sendo que três trabalhos versam sobre a análise geral do documento e dois analisam metas específicas dos Planos. Cabe salientar que, do total de artigos encontrados, apenas um trata do Plano vigente, os demais realizam um balanço sobre o PNE/2001, o que indica a escassez de estudos publicados sobre o planejamento decenal atual.

Na Tabela 4, encontra-se a distribuição quantitativa de trabalhos produzidos que compreendem a temática organizado por região brasileira.

TABELA 4 - VINCULAÇÃO REGIONAL DOS TRABALHOS SOBRE MONITORAMENTO E AVALIAÇÃO DE PLANOS DECENAIS DIVULGADOS NO PORTAL CAPES, SCIELO BRASIL E GT-5/ANPED NACIONAL (2001-2017)

\begin{tabular}{cc}
\hline Região & Qtd. de publicação \\
\hline Sudeste & 4 \\
Nordeste & 1 \\
Norte & 1 \\
Centro-Oeste & 1 \\
Sul & 0 \\
\hline Total & 7 \\
\hline
\end{tabular}

FONTE: Elaboração própria dos autores.

A Tabela 4 demonstra que a maior quantidade de produções acadêmicas publicadas sobre a temática em abordagem encontra-se em instituições localizadas na região Sudeste do Brasil, sendo esta a responsável por 4 (ou 57,14\%) produções de um total de 7 trabalhos levantados. Essa alta concentração de publicações na região Sudeste está em sintonia com o fato desta ser a região geográfica que reúne a maior parte dos programas de pós-graduação e que lidera o ranking de produção do conhecimento do país. 
Chama a atenção, também, além da pouca expressividade dos trabalhos produzidos nas demais regiões do país (responsáveis, cada, por somente 1 ou $14,28 \%$ dos trabalhos totais), a inexistência de produção acadêmica concernente ao tema em foco na região Sul, a segunda de maior destaque no país em termos de concentração da pós-graduação nacional.

No que tange às principais abordagens metodológicas, tipologias de pesquisa e procedimentos de coleta de dados adotados pelos trabalhos analisados, a Tabela 5 é ilustrativa.

TABELA 5 - INCIDÊNCIA DE METODOLOGIAS NOS TRABALHOS SOBRE MONITORAMENTO E AVALIAÇÃO DE PLANOS DECENAIS DIVULGADOS NO PORTAL CAPES, SCIELO BRASIL E GT-5/ANPED NACIONAL

\begin{tabular}{cc}
\hline Metodologias & $\mathbf{N}^{\circ}$ de incidência nos trabalhos \\
\hline Natureza qualitativa & 7 \\
Pesquisa bibliográfica & 7 \\
Análise documental & 7 \\
Análise de conteúdo & 3 \\
Análise comparativa & 2 \\
Estudo de caso & 2 \\
Natureza quali-quantitativa & 1 \\
Análise de dados empíricos & 1 \\
Análise do discurso & 1 \\
\hline Total & $\mathbf{3 1}$ \\
\hline
\end{tabular}

FONTE: Elaboração própria dos autores. Nota (*): A frequência total registrada é 31 porque os 7 trabalhos analisados indicam a utilização de mais de um procedimento metodológico.

Com base nas informações apresentadas na Tabela 5, é possível observar que todas as produções cientificas sob exame ancoram-se na abordagem qualitativa de pesquisa, definida por Esteban (2010, p. 127) como

[...] uma atividade sistemática orientada à compreensão em profundidade de fenômenos educativos e sociais, à transformação de práticas e cenários socioeducativos, à tomada de decisões e também ao descobrimento e desenvolvimento de um corpo organizado de conhecimentos.

A predominância de estudos qualitativos constatada comprova, portanto, $\mathrm{o}$ crescente "[...] interesse que os pesquisadores da área da educação vêm demonstrando pelo uso das metodologias qualitativas" (LÜDKE; ANDRÉ, 1986, p. 11). 
De acordo com as informações da Tabela 5, verifica-se também que a pesquisa bibliográfica é igualmente prevalente nas produções cientificas analisadas, dado que encontra-se em conformidade com a natureza deste tipo de pesquisa, que "[...] constitui o primeiro passo para todas as atividades acadêmicas" (ANDRADE, 2005, p. 39).

Quanto à coleta de dados, a análise documental é a mais frequente e sobressai sobre os demais procedimentos empregados. Sua alta adoção relaciona-se ao fato de tanto poder complementar "[...] as informações obtidas por outras técnicas $[. .$.$] " quanto por permitir desvelar "[...] aspectos novos de um tema ou$ problema" (LÜDKE; ANDRÉ, 1986, p. 38). Outra razão da sua supremacia decorre, provavelmente, do fato de que não é possível monitorar e/ou avaliar a contento os planos decenais de educação sem se debruçar detidamente sobre eles.

\section{Considerações finais}

Nos últimos 17 anos, a produção do conhecimento no Brasil sobre planos decenais tem se mostrado muito escassa. De 2001 a 2017, apenas 85 pesquisas em nível de pós-graduação tiveram como objeto central de análise planos de educação (PNE, PEE ou PME) e somente cinco trabalhos publicadas no GT5 dos encontros nacionais da ANPED trataram da questão. Além de escassa, tal produção caracteriza-se, também, pela recenticidade, uma vez que a grande maioria dos trabalhos foi publicada na corrente década.

Se considerada apenas a produção do conhecimento com foco voltado exclusivamente ao monitoramento e avaliação do planejamento decenal de educação, ela se mostra mais ínfima ainda. A partir do Portal da CAPES, site da ANPED (GT-5) e Scielo Brasil, foram localizados apenas sete pesquisas que abordavam a etapa de monitoramento/avaliação dos planos decenais. Esses dados mostram a carência de estudos na área de planejamento educacional, sobretudo no que compete à avaliação e monitoramento desses documentos.

Embora seja baixíssimo o quantitativo de pesquisas focadas no monitoramento/avaliação dos Planos, as poucas investigações encontradas trazem importantes contribuições para área e suscitam novos pontos de investigação, ainda mais quando analisadas no contexto atual e seguindo as demandas que constam no PNE 2014-2024, tal como a organização de comissões para acompanhar e avaliar os Planos, bem como propor políticas públicas para atendimento das metas existentes nos planos decenais. 
Acredita-se, assim, que o âmbito da avaliação de planos decenais se configura em um campo aberto e profícuo para novas pesquisas, sobretudo no tocante ao processo de monitoramento e avaliação dos Planos, seja na esfera federal, estadual ou municipal. Destaca-se, ainda, a necessidade de estudos que tenham as comissões de acompanhamento dos Planos como objeto central da pesquisa, bem como as ações do poder público a partir dos apontamentos feitos por essas comissões, a fim de superar os entraves e alcançar as metas contidas nos documentos.

Por fim, aponta-se, ainda, a necessidade de investigações no âmbito das avaliações dos Planos que tenham foco mais específico, isto é, pesquisas que analisem, monitorem e avaliem o processo de implementação de metas específicas, pois conforme os dados, apenas dois trabalhos elaborados no período 2001-2017 se debruçaram sobre uma meta específica (meta 7 e 17, respectivamente).

\section{REFERÊNCIAS}

AGUIAR, Márcia Angela da Silva. Avaliação do plano nacional de educação 2001-2009: questões para reflexão. Educ. Soc., Campinas, v. 31, n. 112, p. 707-727, jul.-set. 2010. Disponível em: http://www.cedes.unicamp.br. Acesso em: 21 out. 2018.

ANDRADE, Maria Margarida de. Introdução à metodologia do trabalho cientifico: elaboração de trabalhos na graduação. 7.ed. São Paulo: Atlas, 2005.

ARANDA, Maria Alice de Miranda; LIMA, Franciele Ribeiro. O Plano Nacional de Educação e a busca pela qualidade socialmente referenciada. Revista Educação e Políticas em Debate, v. 3, n. 2, p. 291-313, ago.-dez. 2014.

BORDIGNON, Genuino. Gestão da educação no município: sistema, conselho e plano. São Paulo: Editora e Livraria Instituto Paulo Freire, 2009.

BRASIL. Constituição da República Federativa do Brasil. Diário Oficial da República Federativa do Brasil. Brasília/DF: Senado, 1988.

DI PIERRO, Maria Clara. A educação de jovens e adultos no plano nacional de educação: avaliação, desafios e perspectivas. Educ. Soc. Campinas, v. 31, n. 112, p. 939-959, jul./set. 2010. Disponível em: http://www.cedes.unicamp.br. Acesso em: 21 out. 2018.

DOURADO, Luiz Fernandes. Avaliação do Plano Nacional de Educação 2001-2009: questões estruturais e conjunturais de uma política. Educação e Sociedade, Campinas, v. 31, n. 112, p. 675-705, jul-set. 2010. Disponível em: http://www.scielo.br/pdf/es/ v31n112/03. Acesso em: 29 out. 2017. 
(Org.). Plano Nacional de Educação - PNE 2014/2024: avaliação e perspectivas. Campinas, SP: Mercado de Letras, 2017.

(Org.). A qualidade da educação: conceitos e definições. Brasília: MEC/INEP, 2007.

DRAIBE, Sônia Miriam. Avaliação de implementação: esboço de uma metodologia de trabalho em políticas públicas. In: BARREIRA, Maria Cecília Roxo Nobre; CARVALHO, Maria do Carmo Brant de. (Org.). Tendências e Perspectivas na Avaliação de Políticas e Programas Sociais. São Paulo: IEE/PUC-SP, 2001. p. 13-42.

ESTEBAN, Maria Paz Sandín. Pesquisa qualitativa em educação: fundamentos e tradições. Porto Alegre: AMGH, 2010.

FERREIRA, Norma Sandra de Almeida. As pesquisas denominadas "Estado da Arte". Educação e Sociedade, Campinas, SP, v. 23, n. 79, 2002.

GATTI, Bernardete Angelina. A Construção da Pesquisa em Educação no Brasil. 3 ed. Brasília: Liber Livro Editora, 2010, p. 14-41.

KIPNIS, Bernardo; ALGARTE, Roberto. Planejamento e avaliação educacionais. In: WITTMANN, Lauro Carlos; GRACINDO, Regina Vinhaes (Org.). O Estado da Arte em Política e Gestão da Educação no Brasil 1991-1997. Campinas: Autores Associados; São Paulo: Anpae, 2001. p. 151-171.

LEITE, Y. U. F. et al. Responsabilidades educacionais dos municípios e o compromisso da universidade com a qualidade da educação: uma experiência em andamento. Nuances, ano XVI, v. 17, n. 18, p. 101-124, jan./dez. 2010.

LÜDKE, Menga; ANDRÉ, Marli Eliza Dalmazo Afonso de. Pesquisa em educação: abordagens qualitativas. São Paulo: EPU, 1986.

NASCIMENTO, Gilvânia da Conceição; GROSSI JUNIOR, Geraldo; PEREIRA, Jhonata Moreira. Planos Municipais de Educação: perfil dos municípios que não possuíam plano municipal de educação no segundo ano de vigência da Lei n. 13.005/14. Revista Exitus, Santarém/PA, v. 7, n. 1, p. 108-130, jan./abr. 2017.

PALUMBO, Dennis James. Public policy in America: Government in Action. 2 ed. Orlando/Florida: Harcourt Brasce \& Company, 1994.

SAMPAIO, Carlos Eduardo Moreno. Monitoramento e avaliação do Plano Nacional de Educação. In: DOURADO, Luiz Fernandes Dourado (Org.). Plano Nacional de Educação (2011-2020): avaliação e perspectivas. 2 Ed. Goiânia: Editora UFG; Belo Horizonte: Autêntica Editora, 2011. p. 61-68.

SAVIANI, Dermeval. Sistema Nacional de Educação e Plano Nacional de Educação: Significado, Controvérsias e Perspectivas. Campinas, SP: Autores Associados, 2014.

. Da nova $L D B$ ao FUNDEB: por uma outra política educacional. 2. ed. rev. e ampl. Campinas, SP: Autores Associados, 2008. 
. Sistema Nacional de Educação e Regime de Colaboração. In: BRZEZINSKI, Íria (Org.). LDB 1996 vinte anos depois: projetos educacionais em disputa. São Paulo: Cortez, 2018. p. 27-46.

SCAFF, E. A. da S; OLIVEIRA, M. dos S. de; ARANDA, F. P. N. Planejamento educacional e poder local na elaboração dos planos municipais de educação. Quaestio, Sorocaba, SP, v. 20, n. 1, p. 133-147, abr. 2018.

SILVA, João Henrique; ALMEIDA, Míriam Elena Cesar; CAIADO, Kátia Regina Moreno. Produção do conhecimento sobre as instituições especializadas para a pessoa com deficiência intelectual (1996-2015). Perspectiva, Florianópolis, v. 35, n. 3, p. 859-886, jul./set. 2017.

STREMEL, Silvana. A constituição do campo acadêmico da política educacional no Brasil. Tese (Doutorado em educação) - Universidade Estadual de Ponta Grossa. Ponta Grossa, 2016.

TEIXEIRA, Célia Regina. O "Estado da Arte": a concepção de avaliação educacional veiculada na produção acadêmica do Programa de Pós-Graduação em Educação Currículo (1975-2000). Cadernos de Pós-Graduação: educação, São Paulo, v. 5, n. 1, p. 59-66, 2006.

TRIVIÑOS, Augusto Nibaldo Silva. Introdução à pesquisa em ciências sociais: a pesquisa qualitativa em educação. São Paulo: Atlas, 2007.

Texto recebido em 23/07/2019.

Texto aprovado em 16/09/2019. 